\title{
Clandestine Abortion Complicated by Intestinal Evisceration by Vaginal Route: About a Case at the University Hospital of Brazzaville
}

\author{
Mokoko Jules Cesar', Eouani Levy Max Emery², Buambo Gauthier Regis Jostin ${ }^{1,}$, \\ Potokoue Mpia Sekangue Samantha Nuelly ${ }^{1}$, Elion Ossibi Pierlesky ${ }^{3}$, Nguelongo Berthrand Lori ${ }^{3}$, \\ Itoua Clautaire ${ }^{1}$, Iloki Leon Herve ${ }^{1}$ \\ ${ }^{1}$ Department of Obstetrics Gynecology, University Hospital of Brazzaville, Brazzaville, Congo \\ ${ }^{2}$ Department of Obstetrics Gynecology, Loandjili Hospital, Pointe Noire, Congo \\ ${ }^{3}$ Digestive and Visceral Surgery Department, University Hospital of Brazzaville, Brazzaville, Congo
}

Email address:

jlsmokoko@gmail.com (M. J. Cesar), eouani@yahoo.fr (E. L. M. Emery), buambogauthier@yahoo.fr (B. G. R. Jostin), samanthasekangue@gmail.com (P. M. S. S. Nuelly), ofelion@yahoo.fr (E. O. Pierlesky), dr.loringuelongo@gmail.com (N. B. Lori), clautairei@yahoo.com (I. Clautaire), herviloki@yahoo.fr (I. L. Herve)

${ }^{*}$ Corresponding author

To cite this article:

Mokoko Jules Cesar, Eouani Levy Max Emery, Buambo Gauthier Regis Jostin, Potokoue Mpia Sekangue Samantha Nuelly, Elion Ossibi Pierlesky, Nguelongo Berthrand Lori, Itoua Clautaire, Iloki Leon Herve. Clandestine Abortion Complicated by Intestinal Evisceration by Vaginal Route: About a Case at the University Hospital of Brazzaville. Journal of Gynecology and Obstetrics. Vol. 9, No. 1, 2021, pp. 5-8. doi: $10.11648 /$ j.jgo.20210901.12

Received: January 13, 2021; Accepted: January 27, 2021; Published: January 30, 2021

\begin{abstract}
Introduction. Clandestine abortion, performed under unfavorable conditions, is fraught with complications that can affect both the genitals and extra genitals. Illegal in some developing countries, abortion is responsible for high maternal mortality, of which it is the third cause. Clinical observation. We report the case of a 16-year-old adolescent girl admitted for pelvic pain and genital bleeding with extragenital exteriorization of an intestinal loop following an abortive endo-uterine maneuver, at the end of 16 weeks of amenorrhea depending on the date of the last period. After laparotomy, there was a uterine perforation of the antero-inferior surface with ileo-jejunal evisceration, requiring the performance of an intestinal resection with end-to-end anastomosis and hysterorrhaphy. Conclusion. The complications of clandestine abortions are still relevant in our country, despite the awareness of family planning and contraceptive measures. The lack of a legal framework governing the medical care of abortion leaves free rein to unqualified personnel on the one hand or to artisanal practice on the other, thus exposing them to the risk of high maternal morbidity and mortality.
\end{abstract}

Keywords: Clandestine Abortion, Complications, Uterine Perforation, Brazzaville

\section{Introduction}

Defined by the World Health Organization (WHO), as an abortion performed by an unqualified person, or in an environment that does not comply with minimum medical standards $[1,2]$, clandestine or unsafe abortion is responsible for the consequences disastrous. Its complications can affect both genitals and extra genitals. Illegal in some developing countries, abortion is responsible for high maternal mortality, of which it is the third cause [3]. Worldwide, $88 \%$ of abortions are performed in developing countries [4], including $4.8 \%$ in hospitals in Congo Brazzaville [5]. We report the case of a clandestine abortion complicated by intestinal vaginal evisceration in an adolescent girl, due to its rarity and seriousness.

\section{Clinical Observation}

It was about a 16-year-old primigest teenager, living in Brazzaville, admitted to the University Hospital of Brazzaville, September 14, 2020 at 8 p.m. for pelvic pain and 
genital bleeding with post-abortion extragenital externalization of an intestinal loop in a context of amenorrhea of 16 weeks. Symptoms rose 11 hours before admission, following an abortive endo-uterine maneuver by curettage performed in a nursing office. The patient reported having been taken there by her mother.

On physical examination, the general condition was altered with paleness of the conjunctival mucous membranes and asthenia. Arterial hypotension $(80 / 50 \mathrm{mmHg})$, tachycardia (110 beats per minute) and polypnea ( 24 cycles per min) were noted. The abdomen was supple but tender with pelvic defense. Inspection of the vulva revealed a soft, blackish tubular structure, about two meters long, corresponding to an intestinal loop (Figure 1). On the speculum, the vaginal walls were healthy and the cervix, the site of the gripping impressions of a forceps, allowed the exit of the intestinal loop to be seen through the external opening. On vaginal examination combined with abdominal palpation, the uterus was soft, tender to mobilization and increased in size like a grapefruit.

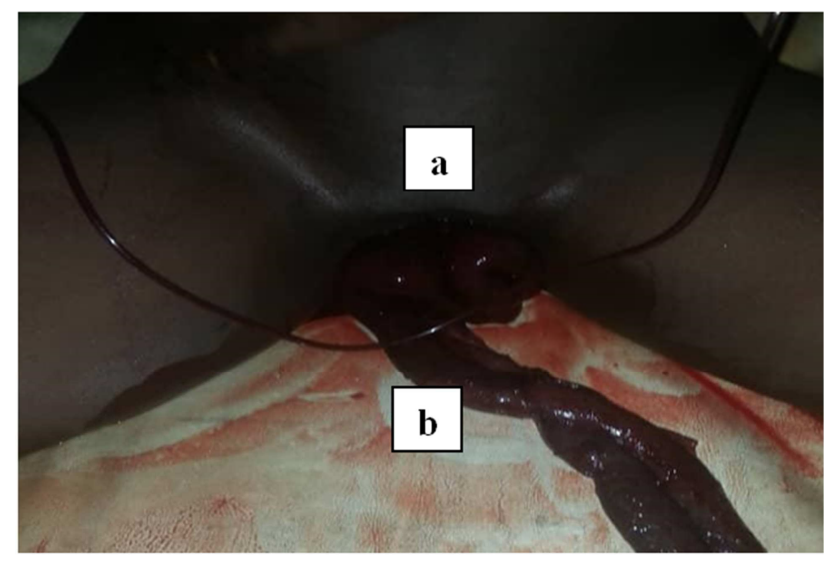

Figure 1. Exit through the vulva of a necrotic intestinal loop (front view)

a. Vulva

b. Necrotic intestinal loop

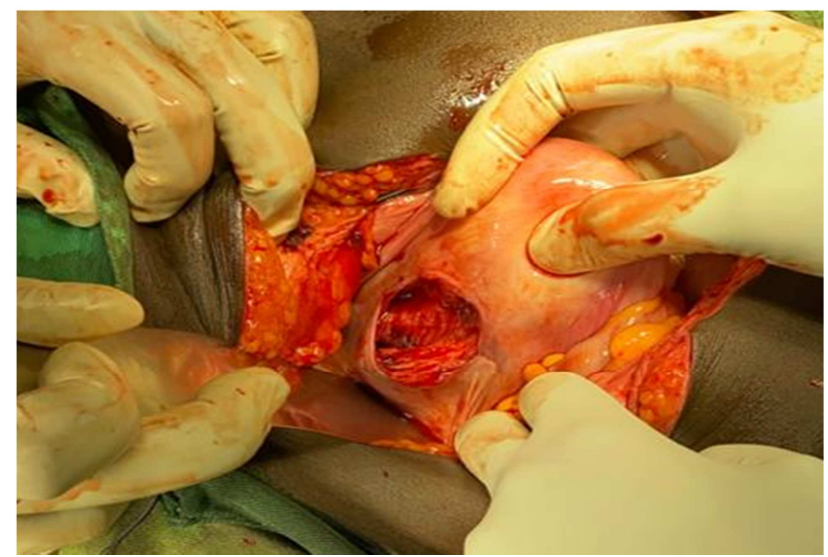

Figure 2. Uterus with a perforation on the antero-inferior surface (anterior view).

a. Body of the uterus (antero-inferior surface)

b. Corporeal-isthmic crater
Pelvic ultrasound revealed a gravid uterus with solution of anterior bodily continuity, containing a fetus without cardiac activity and a heterogeneous intracavitary image merging with the placental echostructure.

The decision for an exploratory laparotomy has been made. It was about a uterine perforation with a corporeal and isthmic crater involving the antero-inferior face, 5 centimeters long axis, as illustrated in figure 2. Evisceration concerned part of the ileum and jejunum. Throttled through the perforation hole. About $500 \mathrm{cc}$ of hemoperitoneum was aspirated.

The surgical procedure consisted of the one hand in a hysterorrhaphy by an extra mucous suture using a 4/1 absorbable suture after having revived the edges, and on the other hand, in an ileo-jejunal resection (figure 3) with end-toend grêlo-hale anastomosis. The operative consequences were simple. The patient stayed for 10 days in the digestive and visceral surgery department.

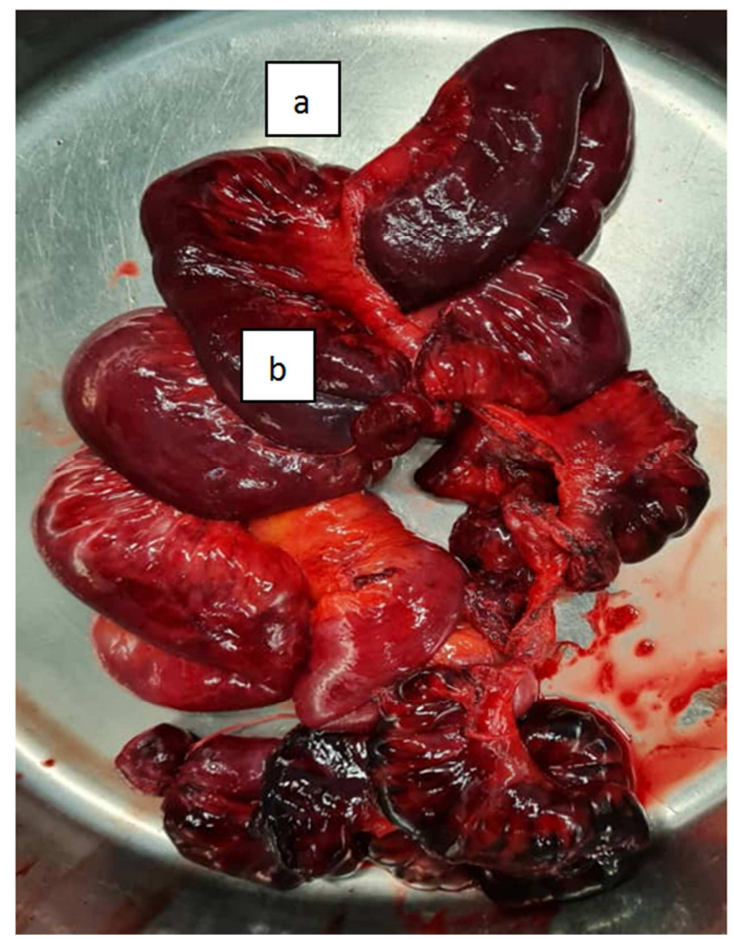

Figure 3. Cup containing a portion of a resected necrotic intestinal loop.

a. Cup

b. Resected portion of the jejunum

\section{Discussion}

The number of voluntary terminations of pregnancies worldwide has only decreased slightly, and half of them are still carried out illegally [1]. In developing countries, the abortion rate first fell between 1995 and 2003 (from $34 \%$ to $29 \%$ ), then remained stable between 2003 and 2008, 97\% of them being illegal or not secured in Africa [1]. This stagnation could probably be explained by a relaxation of efforts in the field of family planning. Indeed, in developing countries, the proportion of women in union practicing contraception, which had increased from $52 \%$ in 1990 to $60 \%$ in 2000 , slowed down 
in the 2000 s, reaching only $61 \%$ in 2009 . [1]. In Congo, the contraceptive prevalence was $20 \%$ in 2011 according to the demographic and health survey http://www.dhsprogram.com/pubs/pdf/OF17/OF17.FF/pdf.

The differentiated evolution of abortions between developed and developing countries has resulted in an increase in the share of clandestine abortions in the world total of abortions, their proportion rising from $44 \%$ in 1995 to $49 \%$ in 2008 [1]. While intestinal wounds during clandestine abortions are increasingly reported [9], postabortion intestinal exenteration remains more exceptional today [10]. The delay in medicosurgical treatment strongly influences the prognosis and increases the risk of peritonitis $[9,10]$. This is a serious situation requiring the mobilization of comprehensive emergency obstetric care and which should not suffer from any diagnostic delay.

The occurrence of complications secondary to an illegal abortion, noted for a quarter of a century in Congo Brazzaville [5], remains relevant today. These abortions are requested by adolescent girls or young women, on average 25 years old, in sexual activity, with an abortive past, who resort to unqualified personnel, thus reflecting the non-satisfaction of contraceptive needs [6-15]. This vulnerable and disadvantaged social layer is paying the heavy price for restrictive abortion laws. More affluent women more often have access to all reproductive health services including voluntary termination of pregnancy abroad. In addition, the financial burden linked to the birth of a child, the double responsibility falling exclusively on the parents due to the refusal of paternity, the stigma relating to the stigmatization of society, and the consequences on schooling, strongly contribute when deciding to terminate the pregnancy, often influenced by the mother and / or partner $[6,15,16]$. Also, an unwanted pregnancy represents a drop in productivity with a significant loss of income. The drop in productivity as well as the drop in income is caused by the need for pregnancy monitoring as well as possible complications during pregnancy, childbirth and postpartum. They can therefore lead to increased poverty and food insecurity [16].

If in some cases, patients self-medicate with illicit drugs [6] and traditional decoctions, however in other cases, they are subject to endo-uterine maneuvers by unqualified people., responsible for serious morbidity [6-15]. Complications of clandestine or unsafe abortions are multiple and of varying severity, dominated in the immediate and short term by hemorrhages, infections, and organ damage [6-15]. Complications in the form of uterine perforation are reported to be frequent in the first trimester $[12,17,18]$ and are preferentially located on the postero-superior surface or in the fundic part of the uterus $[12,19]$, due to its anteversion. it is necessary to overcome by cervical traction. However, in retroverted uteri, the lesion can involve the antero-inferior surface of the uterus, such as was our case. Uterine perforation is most often responsible for a poor general condition with hemodynamic repercussions and multiple organ failure [11]. The severity of postabortion morbidity is proportional to the time to admission, which varies depending on the series [7, 11-3].

While intestinal wounds during clandestine abortions are increasingly reported, postabortion intestinal evisceration remains more exceptional today $[12,20]$. The time taken to medico-surgical treatment strongly influences the prognosis and increases the risk of peritonitis [19, 20]. Kouamé noted $96 \%$ of postabortion peritonitis, including $52.94 \%$ generalized, after an average admission delay of five days [11]. This is a serious situation requiring the mobilization of comprehensive emergency obstetric care and which should not suffer from any diagnostic delay.

The desiccation of the exteriorized intestinal loop and the phenomena of post-ischemic necrosis led to sometimes extensive loop resections, responsible for the deterioration of digestive function, as reported by Lebeau in Abidjan [12]. In addition, the uterine breach constitutes an area of weakness increasing the increased risk of uterine rupture in the event of a previous pregnancy. The obstetric future may be bleaker due to infertility of endometrial origin (uterine synecia) and / or cervical (stenosis, cervico-isthmic open bite).

The consequences of unsafe or clandestine abortion on women's health are serious depending on the method of interruption used, the qualifications of the person performing it, the gestational age of the woman, and the efficiency of the procedure. Health system dealing with postabortion complications. While induced abortions very rarely result in death in developed countries, in 2008 it was estimated that around 2.2 in every 1,000 induced abortions ended tragically in developing countries [21]. In other words, there are estimated to be 40 abortion-related deaths per 100,000 live births in developing countries, which corresponds to $13 \%$ of all maternal deaths (or 1 in 8 maternal deaths) [21]. The rate of death from abortion has declined over the past two decades, from 60 deaths per 100,000 live births to 40 between 1990 and 2008 [22].

\section{Conclusion}

The complications of clandestine abortions are still relevant in our country, despite the awareness of family planning and contraceptive measures. The lack of a legal framework governing the medical care of abortion leaves free rein to unqualified personnel on the one hand or to artisanal practice on the other, thus exposing them to the risk of high maternal morbidity and mortality. A paradigm shift and indepth reflection on the legalization of abortion are more essential and would need to be debated at community, scientific and political level.

\section{Conflicts of Interest}

All the authors do not have any possible conflicts of interest. 


\section{References}

[1] United Nations, Department of Economic and Social Affairs, Population Division, 2011, World Contraceptive Use 2010, http://www.un.org/esa/population/publications/wcu2010/Main .html.

[2] World Health Organisation. Techn Rep Ser 1970, №461. WHO_TRS_461_fre.pdf.

[3] Hilal GF, Thiam O, Leye PA, Ndiaye PI, Diouf E. A Serious Complication of Clandestine Induced Abortions: Septic Shock Secondary to Peritonitis by Cecal Perforation with Retention of Instruments. RAMUR 2014. 19 (1): 87-92.

[4] Guillaume A, Rossier C. Abortion around the World: Status of Legalization, Extent, Trend, and Consequences. Population-F 2018; 73 (2): 225-322. Doi: 10.3917/popu.1802.225.

[5] Iloki LH, Zakouloulou-Massala A, Gbala-Sapoulou MV. Complications of Clandestine Abortions: About 221 Cases Observed at the CHU of Brazzaville (Congo). Med Afr Noire 1997; 44 (5): 262-4.

[6] Mbou Essie DE, Ndinga H, Niama A, Oyere G, Kifoueni G, Ibara JR. Complicated Clandestine Abortions and Street Drugs in Brazzaville. Pan Afr Med Journal 2020; 36: 143. 10.11604/pamj.2020.36.143.18816.

[7] Takongmo S, Nkwabong E, Pisoh-Tanggnying C, Simeu C, Ndiomgba R, Fouda FB. Surgical Complications of Clandestine Abortions: A Review of 51 Patients in Two Hospitals in Yaounde. Clin Mother Child Health 2010; 7: 14.

[8] Mayi-Tsonga S, Diallo T, Litovchenko O, Metogho M, Ndombi I. A Comparative Study of the Complications of Clandestine Abortions: Misoprostol versus other Abortive Methods. Clin Mother Child Health 2009; 6 (1): 983-7.

[9] Mayi-Tsonga S, Diallo $\mathrm{T}$, Litovchenko O, Metogho $\mathrm{M}$, Ndombi I. Prevalence of illegal abortions in Libreville Hospital, Gabon. Bull Soc Pathol Exot 2009; 102 (4): 230-2. Doi: $10.3185 /$ pathexo3403.

[10] Aké-Tano SOP, Kpebo DO, Konan YE and al. Abortion Practices in High School Students in Yamoussoukro, Ivory Coast. Santé publique 2017; 29 (5): 711-17.

[11] Kouamé EK, Pete Y, Yapo YP, Koffi N, Coulibaly KT, N'guessan ML. Complications of Induced Abortions Illegal admitted in ICU in Abidjan (Côte d'Ivoire). Rev Afr Anesth Med Urgence 2014; 19 (1): 24-7.

[12] Lebeau R, Guié P, Bohoussou E and al. An Uncommon Complication of Unsafe Induced Abortion: Bowel Prolapse through Uterine Perforation. Gynecol Obstet Fertil 2013; 41: 193-5.

[13] Ka I, Diop PS, Niang AB, Faye A, Ndoye JM, Fall B. Acute Generalized Peritonitis due to Uterine Perforation following Abortion: Case Study Observation. Pan Afr Med J 2016; 24 : 981-4. Doi: 10.11604/pamj.2016.24.98.9307.

[14] Ouattara A, Ouedraogo A, Ouedraogo CM, Lankoande J. Unsafe Abortions in countries that Restrict Legal Abortions Epidemiologic, Clinical, and Prognostic Aspects at the University Hospital Center Yalgado-Ouédraogo of Ouagadougou. Med Sante Trop 2015; 25: 210-214. Doi: 10.1684/mst.2015.0464.

[15] Osur J, Orago A, Mwanzo I, Bukusi E. Social Networks and Decision Making for Clandestine Unsafe Abortions: Evidence from Kenya. Afr J Reprod Health 2015; 19 (1): 34-43.

[16] Omba KJC. Sexual Violence in Congo-Kinshasa: Necessity of Decriminalizing Abortion. Rev Med Brux 2012, 33: 482-6.

[17] Goran A, Mate M, Tomislav L. Uterine Perforation as a Complication of Surgical Abortion causing Small Bowel Obstruction: A Review. Arch Gynecol Obstet 2013; 288: 31123. Doi: 10.1007/s00404-013-2749-4.

[18] Huei-Ming C, Ching-Ju-S, Cheng-Yeh L, Wing-Mei T. Uterine Perforation, and Bowel Incarceration following Surgical Abortion during the First Trimester. Taiwan J Obstet Gynecol 2008; 47 (4): 448-50.

[19] Harioly Nirina MOJ, Randriambololona DMA, Ranaivo I, Rasolonjatovo T, Rakotoambinima B. Epidemiological Aspect of Post-abortion Pelviperitonitis. Rev Trop Chir 2010; 4: 27-9.

[20] Dossou FM, Hounkpè PC, Tonate Bagnan JA, Denakpo J, Sohou P. Small Bowel Prolapsed through Perforated Uterus following Illegal Induced Abortion. Surgery Curr Res 2012; 2 (4): 1-2.

[21] OMS, 2011, Unsafe abortion: global and regional estimates of the incidence of unsafe abortion and associated mortality in 2008 6th ed., Geneva, World Health Organization.

[22] Åhman E., Shah I. H. New estimates and trends regarding unsafe abortion mortality. Int J Gynecol Obst 2011; 115 (2): $121-6$. 